\title{
PRÁTICAS GERENCIAIS EM MPE'S DO COMÉRCIO DE CONFECÇÕES DA CIDADE DE SOUSA - PB
}

\section{MANAGEMENT PRACTICES OF MPE'S FOR THE CLOTHING MARKET OF THE CITY OF SOUSA - PB}

\section{PRÁCTICAS GERENCIALES EN MPE'S DEL COMERCIO DE CONFECCIONES DE LA CIUDAD DE SOUSA - PB}

\section{JOSÉ RIBAMAR MARQUES DE CARVALHO}

Doutorando em Recursos Naturais - PPGRN/UFCG (Qualis Capes 5)Bolsista CNPq - PPGRN/UFCG. Mestre em Ciências Contábeis UnB/UFPB/UFRN. Professor da Unidade Acadêmica de Ciências Contábeis - Campus Sousa, PB. Endreço: Rua, Sinfrônio Nazaré, 38, Centro, Sousa, PB. CEP: 58.240-000. E-mail: profribamar@gmail.com

\section{MARIA DAS DORES LIMA}

Graduada em Ciências Contábeis - Universidade Federal de Campina Grande. Centro de Ciências Jurídicas e Sociais - UACC/UFCG. Endereço: Rua, Sinfrônio Nazaré, 38, Centro, Sousa, PB. CEP: 58.240-000. E-mail: dorynhalyma@hotmail.com

\section{RESUMO}

Este estudo tem por objetivo analisar quais as práticas gerenciais utilizadas pelas micro e pequenas empresas do setor de confecções da cidade de Sousa/PB, bem como identificar clusters de acordo com as opiniões dos gestores entrevistados, visando conhecer melhor as estratégias utilizadas nessas organizações em relação às práticas de gerenciamento. O método utilizado foi o dedutivo e a pesquisa foi do tipo exploratória com abordagem quantitativa 
e caráter descritivo. A amostragem foi do tipo não probabilística e contemplou 45 empresas. Os resultados apontam, de uma maneira geral, que as empresas do comércio varejista de confecções da cidade de Sousa/PB fazem uso de práticas gerenciais com ordenação intuitiva e baseadas na experiência de cada gestor, no entanto, isso ocorre de forma desordenada e de maneira informal, sem definir um plano estruturado e consistente capaz de amenizar os gargalos existentes no processo de decisão, bem como as mutações constantes nos cenários em que se encontram inseridas. Sugere-se que o estudo seja replicado com o uso da escala de Likert e com um maior número de empresas, bem como em outros segmentos de modo que se possa visualizar resultados mais satisfatórios.

Palavras-chave: Micro e Pequenas Empresas; Práticas Gerenciais; Comércio Varejista de Confecções.

\section{SUMMARY}

The objective of this study is to analyze which managerial practices are utilized by small and micro businesses in the clothing sector of the state of Sousa/PB, as well as identify clusters in accordance with the opinions of the interviewed managers, aiming for a better understanding of the strategies utilized within these organizations in relation to managerial practices. The method utilized was deductive and the research was of an exploratory nature, with a quantitative approach and descriptive character. The sample was of a nonprobabilistic type taken with 45 businesses. The results indicate, in a general manner, that the businesses of the retail clothing market of the city of Sousa/PB use managerial practices by an intuitive order and based on the experience of each manager. However, this occurs in a disordered fashion and in an informal manner, without defining a structured and consistent plan capable of easing the pitfalls within the decision process, as well as the constant mutations of the settings in which they are embedded. It is suggested that the study be replicated with the use of the Likert scale and with the greatest number of businesses, as well as in other segments, in order to gain a better view of the results.

Key-words: Small and Micro Businesses; Management Practices; Retail Clothing Market.

\section{RESUMEN}

Este estudio tiene por objetivo analizar cuáles son las prácticas gerenciales utilizadas por las micro y pequeñas empresas del sector de confecciones de la ciudad de Sousa/ $\mathrm{PB}$, así como identificar clústeres de acuerdo con las opiniones de los gestores entrevistados, visando conocer mejor las estrategias utilizadas en esas organizaciones en relación a las prácticas de gerenciamiento. El método utilizado fue el deductivo y la pesquisa fue 
del tipo exploratoria, con abordaje cuantitativo y carácter descriptivo. El muestreo fue del tipo no probabilístico junto a 45 empresas. Los resultados apuntan de una manera general que las empresas del comercio detallista de confecciones de la ciudad de Sousa/PB hacen uso de prácticas gerenciales con ordenación intuitiva y basada en la experiencia de cada gestor, no obstante, eso ocurre de forma desordenada y de manera informal sin definir un plan estructurado y consistente capaz de amenizar los obstáculos existentes en el proceso de decisión, así como las mutaciones constantes en los escenarios en que se encuentran inseridas. Se sugiere que el estudio sea replicado con el uso de escala de Likert y con un mayor número de empresas, así como en otros segmentos de modo que puedan visualizarse resultados más satisfactorios.

Palabras clave: Micro y Pequeñas Empresas; Prácticas Gerenciales; Comercio Detallista de Confecciones.

\section{INTRODUÇÃO}

Entende-se que atualmente os empresários, em especial os gestores das micro e pequenas empresas (MPEs), por motivos principalmente relacionados ao baixo grau de instrução, acabam deixando de dar importância às informações contábeis e, consequentemente, à adoção de técnicas gerenciais capazes de subsidiar suas decisões empresariais, uma vez que ao gestor cabe a tarefa de gerenciar seu(s) negócio(s).

Notadamente o segmento das MPEs exerce forte influência na economia do país. Todavia, as atividades dessas organizações estão sendo encerradas cada vez mais cedo, de acordo com uma pesquisa realizada pelo SEBRAE (2007). No Brasil, as MPEs representam uma parcela bastante representativa do conjunto de empresas. Essas empresas, de acordo com o SEBRAE (2007), respondem por 99,2\% do número total das empresas formais, por $57,2 \%$ dos empregos totais e por $26,0 \%$ da massa salarial brasileira. A importância desse grupo de empresas para o cenário empresarial foi descrita por Longernecker et al. (1997) e Callado et al. (2008) ao afirmarem que as pequenas organizações, como parte da comunidade empresarial, contribuem para o bem-estar econômico da nação, pois produzem uma parte substancial do total de bens e serviços, contribuindo assim de forma similar às grandes empresas.

Desse modo, dada a sua importância no contexto das organizações, entende-se que a utilização de práticas de gerenciamento empresarial pode contribuir para o acompanhamento e aperfeiçoamento das decisões a serem tomadas pelos gestores, especificamente quando se refere ao processo de medição de desempenho, até porque só é possível avaliar e gerenciar quando se mede (KAPLAN; NORTON, 1997, p.21). Ou ainda "[...] o que é medido e usado nas avaliações é gerenciado" (SALTERIO; WEBB, 2003, p. 41). 
Silva et al. (2002, p.24) dizem que a decisão de investir, de reduzir custos, de modificar uma linha de produtos ou de praticar outros atos gerenciais deve basear-se em dados técnicos extraídos dos registros contábeis, sob pena de se pôr em risco o patrimônio da empresa.

Do exposto, fica evidente que a Contabilidade Gerencial, por meio de suas práticas, tenta auxiliar e direcionar o conhecimento necessário a ser aplicado por cada gestor na tomada de decisão.

Com base nessas premissas e levando-se em consideração a importância do segmento em estudo, especificamente na região do sertão paraibano por ser um segmento sobre o qual não existem pesquisas com essa preocupação (ao menos foi o que se constatou), surgiu interesse em analisar quais as práticas gerenciais utilizadas nas empresas do comércio varejista de confecções da cidade de Sousa-PB, bem como identificar clusters de acordo com as opiniões dos gestores entrevistados, visando conhecer melhor as estratégias utilizadas nessas organizações em relação a tais práticas.

Assim sendo, espera-se que o presente estudo possa contribuir para o desenvolvimento de novas práticas necessárias ao processo decisório, na tentativa de que o desempenho empresarial possa ser aperfeiçoado da melhor maneira possível.

O estudo concentra-se na cidade de Sousa, Paraíba, posto ser uma cidade polo do sertão paraibano e dispor de um comércio varejista de confecções de grande importância para o desenvolvimento econômico regional.

\section{MARCO TEÓRICO}

\subsection{Práticas Gerenciais}

As práticas gerenciais constituem elementos que dinamizam o cotidiano de organizações. As ações dos dirigentes voltam-se para diferentes setores estando diante das especificidades das decisões face ao tipo de tarefa e aos agentes organizacionais. As origens, a história e os aspectos contextuais marcam a vida das organizações, abrindo a perspectiva da consideração de aspectos culturais presentes nessas decisões e ações, próprios à cultura organizacional e à cultura nacional (MAIA, 2008).

De acordo com Maximiano (2000), as práticas de gestão encarregam-se da definição de objetivos e organização de pessoas, do controle e andamento das atividades e da avaliação do desempenho da empresa.

Conforme Maia (2008), essas práticas fazem parte do cotidiano das organizações, podendo ser apreendidas em empresas no âmbito de recursos humanos, financeiros, mercadológicos e de produção que, no caso de empresas comerciais, envolve a área de logística e operações. $\mathrm{Na}$ área financeira controlam-se os pagamentos e recebimentos, as operações de faturamento, o crédito e a cobrança e o financiamento (GITMAN, 1984). Envolve investimento, além de orientação para a administração dos recursos financeiros existentes (ROSS et al., 1995). 
O que se verifica dentro desse contexto é que a maneira e a forma como determinadas práticas gerenciais são utilizadas no processo de gestão influenciam diretamente o desempenho da organização e consequentemente a continuidade das atividades empresariais. Para Callado et al. (2008 apud ZIMMERER; SCARBOROUGH, 1994) as causas existentes para que os pequenos empresários não tenham êxitos em seus negócios são diversas, mas os principais motivos para os insucessos dos pequenos empreendimentos são: incompetência administrativa; falta de experiência; falta de controle financeiro adequado; falta de capital de giro; expansão não planejada; falhas no planejamento e falta de controle de estoque.

\subsection{Contabilidade Gerencial como Instrumento de Administração}

De acordo com Santos et al. (2005), a Contabilidade Gerencial é um processo de identificação, mensuração, acumulação, análise, preparação, interpretação e comunicação de informações passadas, atuais ou futuras necessárias e úteis para auxiliar os gestores no planejamento diário e futuro das organizações.

Dessa forma, os administradores utilizam informações contábeis para escolher, comunicar e implantar estratégias, objetivando gerar valor para garantir o sucesso das organizações (HORNGREN et al., 2004).

Garrison et al. (2007, p. 4), dizem que a Contabilidade Gerencial preocupa-se com o fornecimento de informações aos administradores, ou seja, aos indivíduos no interior de uma organização, que dirigem e controlam as operações. "Assim [...] toda organização - pequena e grande - possui administradores". Alguém precisa ser responsável pela elaboração de planos, pela organização de recursos, pela direção de pessoas e pelo controle de operações.

Por sua vez, Pizzolato (2004, p.195) afirma que a Contabilidade Gerencial está voltada para a informação contábil que pode ser útil à administração, de forma adequada para assessorar os processos decisórios.

As empresas obtêm sucesso e prosperam com base na elaboração de produtos e de serviços que os clientes valorizam, embora a informação gerencial contábil não possa garantir o sucesso desses serviços, seu mau funcionamento resultará em severas dificuldades para as empresas. Sistemas de Contabilidade Gerencial efetivos podem criar valores consideráveis, fornecendo informações precisas a tempo hábil sobre as atividades requeridas para o sucesso das empresas atuais (PERES, 2000).

Aguiar e Frezatti (2007) argumentam que uma das tendências para identificar e analisar a estrutura apropriada de um sistema de controle gerencial é a análise do seu relacionamento com o desempenho organizacional, considerando o efeito de variáveis contingentes. Para esses autores, uma estrutura apropriada seria aquela que está associada com maior desempenho organizacional, sendo essa associação moderada por variáveis contingentes (tais como, ambiente, tecnologia, estratégia etc.). 
Percebe-se, segundo os estudiosos, que um sistema de controle gerencial estará cumprindo com seu papel organizacional quando estiver adequado às demais variáveis do processo de estratégia e que a referida adequação tem um impacto positivo sobre o desempenho organizacional.

\subsection{Alguns estudos sobre Micro e Pequenas Empresas no Brasil}

Nesta seção são apresentados alguns estudos desenvolvidos no Brasil em relação às micro e pequenas empresas, nos quais são transcorridas informações sobre o foco da pesquisa e os potenciais resultados, visando respaldar ainda mais o presente estudo.

Sales et al. (2008) desenvolveram um estudo visando identificar as características específicas de 32 empreendimentos produtivos que não sobreviveram na cidade de Leopoldina - MG, entre os anos de 2000 e 2005, e os fatores condicionantes da mortalidade dessas empresas. Os resultados obtidos pelos autores apontam para uma taxa de mortalidade muito acima da média do Brasil e de Minas Gerais. Destacaram-se como fatores mais importantes para o fechamento das empresas os problemas particulares dos sócios, a falta de clientes, a crise econômica e o ambiente de negócios desfavorável. Porém, os resultados da pesquisa apontam que esses fatores não podem ser responsabilizados isoladamente por essa mortalidade, visto que a concorrência muito forte e a carga tributária elevada também apresentaram altos índices de respostas.

Ferreira e Santos (2008) analisaram os fatores contribuintes para a mortalidade precoce de micro e pequenas empresas de São Paulo, especialmente no que diz respeito ao empreendedor, à empresa e ao ambiente externo. $O$ método de pesquisa foi explicativo e partiu de 16 hipóteses para a mortalidade das MPEs. No estudo foi selecionada uma amostra de 100 microempresários que constituíram MPE entre os anos de 2003 e 2005 e tiveram suas empresas extintas em 2005. O instrumento para a coleta de dados foi a entrevista. Os resultados apresentados por esses autores buscam avaliar em que medida os fatores contribuíram para a extinção das empresas. Este trabalho busca contribuir para o entendimento da realidade do fenômeno de mortalidade precoce das MPEs, apresentando um conjunto de conclusões e recomendações gerenciais destinadas a contribuir para a redução das taxas de mortalidade de MPEs, que têm função importante no desenvolvimento da economia no Brasil.

Fernandes et al. (2008) procuraram identificar como ocorre a aprendizagem organizacional em microempresas. Os resultados mostram que os indivíduos, na microempresa estudada, aprendem pela experiência e pela interação, mas passam pelo processo de aprendizagem organizacional sem dele ter consciência clara, em função do que é aprendido pela via da dimensão tácita do conhecimento, o que corrobora a importância da aprendizagem informal e da aprendizagem incidental.

Tavares et al. (2008) analisaram práticas e atitudes gerenciais propostas pela Teoria Administrativa no processo de decisão, baseando-se no nível de complexidade e de ade- 
quação da gestão ao ambiente de negócios. Esse estudo mostra que as atitudes e práticas gerenciais podem contribuir para a exploração das técnicas e práticas em favor de ganhos de qualidade que reflitam em benefícios diretos aos empresários, com externalidades positivas para a sociedade e para o desempenho da economia regional.

Callado et al. (2008) identificaram estrutura e padrões de relações existentes entre as principais variáveis relativas ao uso da Contabilidade de Custos nas micro e pequenas organizações industriais localizadas na cidade de João Pessoa, PB, por meio da aplicação da análise de agrupamento e análise fatorial sobre as principais variáveis relacionadas à gestão de custos. Os resultados encontrados pelos autores revelam indícios relevantes para uma compreensão mais ampla sobre as principais implicações das práticas relacionadas à contabilização dos custos em organizações industriais, bem como destacam que as práticas gerenciais e administrativas devem considerar esses resultados relevantes para estabelecer rotinas de trabalho.

Raifur et al. (2009) identificaram as principais características de estrutura, financiamento e gestão do capital de giro nas Micro e Pequenas Empresas (MPEs) em 76 micro e pequenas empresas. Os resultados apontam que o tempo de permanência das MPEs no mercado implica maiores oportunidades de geração de emprego e renda. As vendas dessas empresas dependem da concessão de crédito, cuja política situa-se entre 30 e 90 dias. Argumentam ainda que as principais fontes espontâneas utilizadas são os fornecedores e as não espontâneas são a antecipação de recebíveis e os limites bancários. A forma de pagamento mais utilizada é o cartão de crédito que, por sua vez, apresenta o menor índice de inadimplência, enquanto o crediário possui índice significativamente mais elevado. Segundo esses autores a competição exerce influência na política de crédito e baliza a formação de preços. Há elevada insatisfação com relação ao custo de empréstimos e as maiores barreiras na obtenção dos recursos são o cadastro em órgãos de proteção ao crédito e a falta de garantias reais.

Bavaresco e Gaspareto (2009) investigaram como as informações contábeis são utilizadas pelos gestores de micro e pequenas empresas na tomada de decisão, sendo pesquisadas as empresas catarinenses finalistas do Prêmio Talentos Empreendedores, promovido pelo SEBRAE, edição de 2007. Dentre os resultados da pesquisa, verificou-se que a maioria dessas empresas utiliza instrumentos básicos de controle financeiro, com dados provenientes de controles específicos da área financeira, sem integração com a Contabilidade; a maioria delas também elabora planejamento orçamentário e calcula os custos dos produtos ou serviços; porém, na constituição da empresa, grande parte dos respondentes não realizou estudo do ambiente econômico e financeiro em que iriam atuar. Observa-se que essas micro e pequenas empresas utilizam instrumentos de gestão simples, mas carecem de apoio da ontabilidade, que é ainda considerada um provedor de informações com caráter prioritariamente burocrático e fiscal. 


\section{PROCEDIMENTOS METODOLÓGICOS}

Tendo em vista a necessidade de compreender o problema, o método utilizado foi o dedutivo e a pesquisa foi do tipo exploratório, com abordagem quantitativa e caráter descritivo.

Para a realização do estudo foi elaborado um questionário com perguntas dicotômicas direcionadas aos gestores das MPEs do comércio varejista de confecções da cidade de SousaPB. Baseada nos dados obtidos durante o estudo de campo foi feita uma análise das práticas gerenciais que estão sendo utilizadas no processo de decisão.

\subsection{Delimitação e Amostra do Setor Estudado}

A pesquisa foi realizada no comércio varejista de confecções da cidade de Sousa/PB, durante o primeiro semestre de 2009. O porte das empresas foi definido de acordo com a metodologia do SEBRAE que adota o critério de números de empregados para classificar as empresas. A população total do estudo corresponde a 165 empresas de acordo com o Cadastro do Contribuinte dos Impostos Sobre Mercadorias e Serviços - Coletoria Estadual de Sousa (CCMS). No entanto, a pesquisa foi realizada com uma amostra não probabilística e por acessibilidade em 45 empresas, visto que algumas delas não foram localizadas e outras não responderam o questionário.

Percebeu-se que algumas informações do referido cadastro estavam desatualizadas, bem como algumas organizações estavam cadastradas muito embora não estivessem mais funcionando, motivo que inviabilizou o contato com um maior número de organizações.

\subsection{Instrumentos de Coleta de dados e Tratamento Estatístico}

$O$ instrumento de coleta de dados utilizado para a presente pesquisa foi um questionário, semi-estruturado (conforme apêndice desse estudo), que procurava investigar variáveis relacionadas às características do entrevistado, características das empresas e características das práticas empresariais de gestão.

As análises foram procedidas a partir das técnicas da estatística descritiva, da análise de cluster (aglomerado), bem como do teste de consistência interna Alfa de Cronbach e todas foram realizadas com o uso do Statistical Package for Social Science (SPSS), versão 8.0.

\section{ANÁLISE DOS RESULTADOS}

Este tópico mostra os resultados obtidos pela pesquisa com o uso da análise dos dados coletados por meio de um questionário com perguntas estruturadas e objetivas, acerca das práticas de gerenciamento utilizadas pelas empresas do comércio de confecções da cidade de Sousa/PB. Inicialmente são analisadas as características dos entrevistados, posteriormente a caracterização das organizações pesquisadas e das práticas empresariais utilizadas, bem como a identificação dos clusters encontrados. 


\subsection{Caracterização dos Entrevistados: Estatística Descritiva}

Inicialmente, os resultados encontrados nas análises realizadas mostram que dos 45 gestores entrevistados, 51,1\% exercem a função de proprietários, 37,8\% classificamse como gerentes e 4,4\% são diretores. Apenas 2,2\% dos respondentes são classificados como outros, já que não identificaram a função. No que se refere ao tempo de experiência do entrevistado verificou-se que $40,0 \%$ dos respondentes atuam no ramo de confecções há mais de 10 anos, 31,1\% atuam no mercado entre 4 e 10 anos, 22,2\% entre 1 e 3 anos e $6,7 \%$ atuam há menos de 1 ano no mercado. Percebe-se que a experiência dos entrevistados no segmento é razoável, quando se observa que 18 dos 45 entrevistados têm um bom tempo de atuação no mercado (acima de 10 anos).

No tocante à variável do grau de instrução dos entrevistados, percebe-se que existe uma diversidade, visto que a grande maioria das pessoas apenas cursou o ensino médio, obtendo $57,8 \%$ dos entrevistados, e apenas $11,1 \%$ cursaram ensino superior e $8,9 \%$ não concluíram o ensino médio. Apenas 4,4\% têm formação em nível de pós-graduação ou ainda não concluíram o ensino superior e 13,4\% apresentam outros níveis de escolaridade (não responderam).

\subsection{Características das Empresas Pesquisadas: Estatística Descritiva}

A peculiaridade do setor em relação à natureza jurídica está concentrada em empresas individuais, a grande maioria das empresas em estudo, 97,8\%, classifica-se como sendo dessa natureza e apenas $2,2 \%$, como sociedade empresarial limitada.

No tocante ao regime de tributação, foi possível perceber que a grande maioria $(91,1 \%)$ das empresas pesquisadas está enquadrada no regime de tributação simples nacional. Apenas 2,2\% optaram pelo regime tributário de Lucro Real ou Lucro Presumido. Acrescente-se ainda que 4,5\% não responderam qual seu tipo de tributação.

Em relação ao tempo de atividade do empreendimento, verifica-se que 33,4\% atuam no mercado há mais 10 anos, 24,4\% atuam no mercado entre 2 e 5 anos, $17,8 \%$ detêm um tempo de atividade entre 6 e 8 anos, apenas $11,1 \%$ atuam há menos de 1 ano.

\subsection{Características das Práticas Gerenciais Utilizadas: Estatística Descritiva}

Na tabela 1, é possível observar quais as práticas de gerenciamento utilizadas pelos gestores das empresas investigadas. Os resultados evidenciam que $97,8 \%$ das empresas possuem um controle de contas a pagar; 93,4\% fazem o controle de contas a receber, possuem o controle de caixa e têm conhecimento do mercado onde atuam fazendo com que tenham um bom aproveitamento das oportunidades de negócios; $86,7 \%$ fazem controle de vendas e $75,6 \%$ possuem controle dos estoques. Observa-se ainda que $95,6 \%$ dos gestores têm capacidade de liderança e reinvestem os lucros na própria empresa, por sua vez, $75,6 \%$ utilizam capital próprio, 82,3\% utilizam a capacidade de assumir riscos. Entende-se que mesmo não utilizando sistemas de gerenciamento, conforme o que preceitua a literatu- 
ra, há uma utilização de práticas informais que supostamente estão subsidiando a tomada de decisões empresariais.

Tabela 1 - Distribuição das práticas de gerenciamento utilizadas pelas empresas

\begin{tabular}{|l|c|c|c|c|c|c|c|}
\hline \multicolumn{1}{|c|}{ Práticas Gerenciais } & Sim & $\%$ & Não & $\%$ & N.R. & $\%$ & Total \\
\hline 1. Controle de contas a pagar & 44 & $97,8 \%$ & 1 & $2,2 \%$ & 0 & 0 & $100 \%$ \\
\hline 2. Controle de contas a receber & 43 & $95,6 \%$ & 1 & $2,2 \%$ & 1 & $2,2 \%$ & $100 \%$ \\
\hline 3. Controle de caixa & 42 & $93,3 \%$ & 3 & $6,7 \%$ & 0 & 0 & $100 \%$ \\
\hline 4. Controle de vendas & 39 & $86,7 \%$ & 6 & $13,3 \%$ & 0 & 0 & $100 \%$ \\
\hline 5. Controle de estoques & 34 & $75,6 \%$ & 11 & $24,4 \%$ & 0 & 0 & $100 \%$ \\
\hline 6. Evolução do volume de vendas & 31 & $68,9 \%$ & 13 & $28,9 \%$ & 1 & $2,2 \%$ & $100 \%$ \\
\hline $\begin{array}{l}\text { 7. Conhecimento das potencialidades e } \\
\text { fraquezas dos concorrentes }\end{array}$ & 16 & $35,6 \%$ & 28 & $62,2 \%$ & 1 & $2,2 \%$ & $100 \%$ \\
\hline 8. Previsão de vendas e previsão de despesas & 29 & $64,5 \%$ & 15 & $33,3 \%$ & 1 & $2,2 \%$ & $100 \%$ \\
\hline 9. Observação dos prazos de vendas & 35 & $77,8 \%$ & 9 & $20,0 \%$ & 1 & $2,2 \%$ & $100 \%$ \\
\hline 10. Conhecimento do mercado onde atua & 42 & $93,3 \%$ & 3 & $6,7 \%$ & 0 & 0 & $100 \%$ \\
\hline 11. Aproveitamento das oportunidades de negócios & 41 & $91,1 \%$ & 4 & $8,9 \%$ & 0 & 0 & $100 \%$ \\
\hline 12. Empresário com persistência ou perseverância & 44 & $97,8 \%$ & 1 & $2,2 \%$ & 0 & 0 & $100 \%$ \\
\hline $\begin{array}{l}\text { 13. Reinvestimentos dos lucros na própria } \\
\text { empresa }\end{array}$ & 43 & $95,6 \%$ & 1 & $2,2 \%$ & 1 & $2,2 \%$ & $100 \%$ \\
\hline 14. Uso de capital próprio & & & & & & & \\
\hline 15. Criatividade do empresário & 34 & $75,6 \%$ & 10 & $22,2 \%$ & 1 & $2,2 \%$ & $100 \%$ \\
\hline 16. Estratégia de vendas & 42 & $93,4 \%$ & 2 & $4,4 \%$ & 1 & $2,2 \%$ & $100 \%$ \\
\hline 17. Capacidade de liderança do empresário & 43 & $93,3 \%$ & 3 & $6,7 \%$ & 0 & 0 & $100 \%$ \\
\hline $\begin{array}{l}\text { 18. Capacidade do empresário para assumir } \\
\text { riscos }\end{array}$ & 37 & $82,3 \%$ & 6 & $13,3 \%$ & 2 & $4,4 \%$ & $100 \%$ \\
\hline
\end{tabular}

Fonte: Dados primários da pesquisa, 2009.

\subsection{Similaridade das Práticas Gerenciais Utilizadas: Análise de Clusters}

Para identificar a tendência dos estilos das práticas gerenciais das empresas pesquisadas, foi utilizada a análise de cluster (agrupamentos), que é o nome dado às técnicas de análise que dividem os dados em grupos, classificando objetos ou indivíduos em grupos homogêneos. Isto é, observando apenas as similaridades ou dissimilaridades entre eles (MAROCO, 2003).

Neste estudo se propôs a determinar em qual cluster se insere cada uma das opiniões dos gestores em relação às práticas de gerenciamento, permitindo avaliar algumas características semelhantes de atuação, em função de aspectos regionais. 
O método utilizado neste estudo foi o Ward que é derivado do processo de aglomeração hierárquico e aglomerativo (MALHOTRA, 2001, p.531). Método que segundo Hair et al. (2005, p. 383) "é um procedimento de agrupamento hierárquico no qual a similaridade usada para juntar agrupamentos é calculada com a soma de quadrados entre os dois agrupamentos somados sobre todas as variáveis". Para os autores, esse método tende a resultar em agrupamentos de tamanhos aproximadamente iguais devido a sua minimização de variância interna.

De acordo com Roses e Leis (2002), no processo aglomerativo cada objeto tem início em um conglomerado separado. Formam-se os conglomerados agrupando-se os objetos em conglomerados cada vez maiores. No método de variância, os conglomerados são gerados de modo a minimizar a variância dentro do conglomerado. Finalmente, no método de Ward, o objetivo é minimizar o quadrado da distância euclidiana às médias dos conglomerados.

Os resultados demonstram que a primeira linha representa o estágio 1 no qual estão combinadas as práticas gerenciais 12 (Empresário com persistência ou perseverancia) e 17 (Capacidade de liderança do empresário) conforme mostra a coluna os clusters combinados (tabela 2). Verifica-se que estas duas práticas foram aglomeradas no primeiro estágio por apresentarem a menor distância euclidiana entre si 0,50 (medida mais comumente usada da similaridade entre dois objetos - Hair et al. 2005). De maneira análoga, as demais práticas foram aglomeradas conforme demonstra a tabela a seguir. 
Tabela 2 - Calendário de aglomeração das práticas empresariais utilizadas (Método de Ward)

\begin{tabular}{lrrrrrr}
\hline \hline & & & \multicolumn{2}{c}{ Estágio em que o primeiro } & \\
Estágio & Clusters Combinado & Coeficiente & cluster aparece & Próximo \\
\cline { 2 - 3 } & Cluster 1 & Cluster 2 & de distância & Cluster 1 & Cluster 2 & estágio \\
\hline 1 & 12 & 17 &, 500 & 0 & 0 & 3 \\
2 & 13 & 16 & 2,000 & 0 & 0 & 6 \\
3 & 12 & 15 & 3,500 & 1 & 0 & 10 \\
4 & 1 & 11 & 5,000 & 0 & 0 & 6 \\
5 & 3 & 10 & 7,000 & 0 & 0 & 8 \\
6 & 1 & 13 & 9,500 & 4 & 2 & 7 \\
7 & 1 & 2 & 12,000 & 6 & 0 & 8 \\
8 & 1 & 3 & 14,857 & 7 & 5 & 10 \\
9 & 4 & 5 & 18,357 & 0 & 0 & 14 \\
10 & 1 & 12 & 22,300 & 8 & 3 & 12 \\
11 & 6 & 8 & 27,300 & 0 & 0 & 13 \\
12 & 1 & 18 & 32,864 & 10 & 0 & 15 \\
13 & 6 & 9 & 39,864 & 11 & 0 & 16 \\
14 & 4 & 14 & 47,697 & 9 & 0 & 15 \\
15 & 1 & 4 & 56,286 & 12 & 14 & 17 \\
16 & 6 & 7 & 67,536 & 13 & 0 & 17 \\
17 & 1 & 6 & 94,167 & 15 & 16 & 0 \\
\hline \hline
\end{tabular}

Fonte: Dados primários da pesquisa, 2009.

Corroborando os dados da tabela 2, foi utilizada outra forma de visualizar o resultado do processo de aglomeração (figura 1). Nessa figura, as linhas representam os números de conglomerados e as colunas, por sua vez, as variáveis que estão sendo aglomeradas, nesse caso, as práticas gerenciais empresariais utilizadas no segmento de confecções em estudo. A observação a ser feita é de baixo para cima (observando aquelas que estão bem mais preenchidas). No caso em estudo, observa-se novamente que as práticas 12 e 17, respectivamente, apresentam a coluna totalmente preenchida. Essa característica, segundo Roses e Leis (2002), denota que esses são os primeiros objetos aglomerados e, assim por diante, os demais são aglomerados, diminuindo o tamanho da coluna. Dessa forma, verifica-se que as práticas gerenciais $12,17,15,13,10,3,16,1$ e 11 formam o cluster 1 e as práticas $2,18,4,5,14,6,8,9$ e 7 o cluster 2 . 
Figura 1 - Barras Verticais segundo o Método Ward

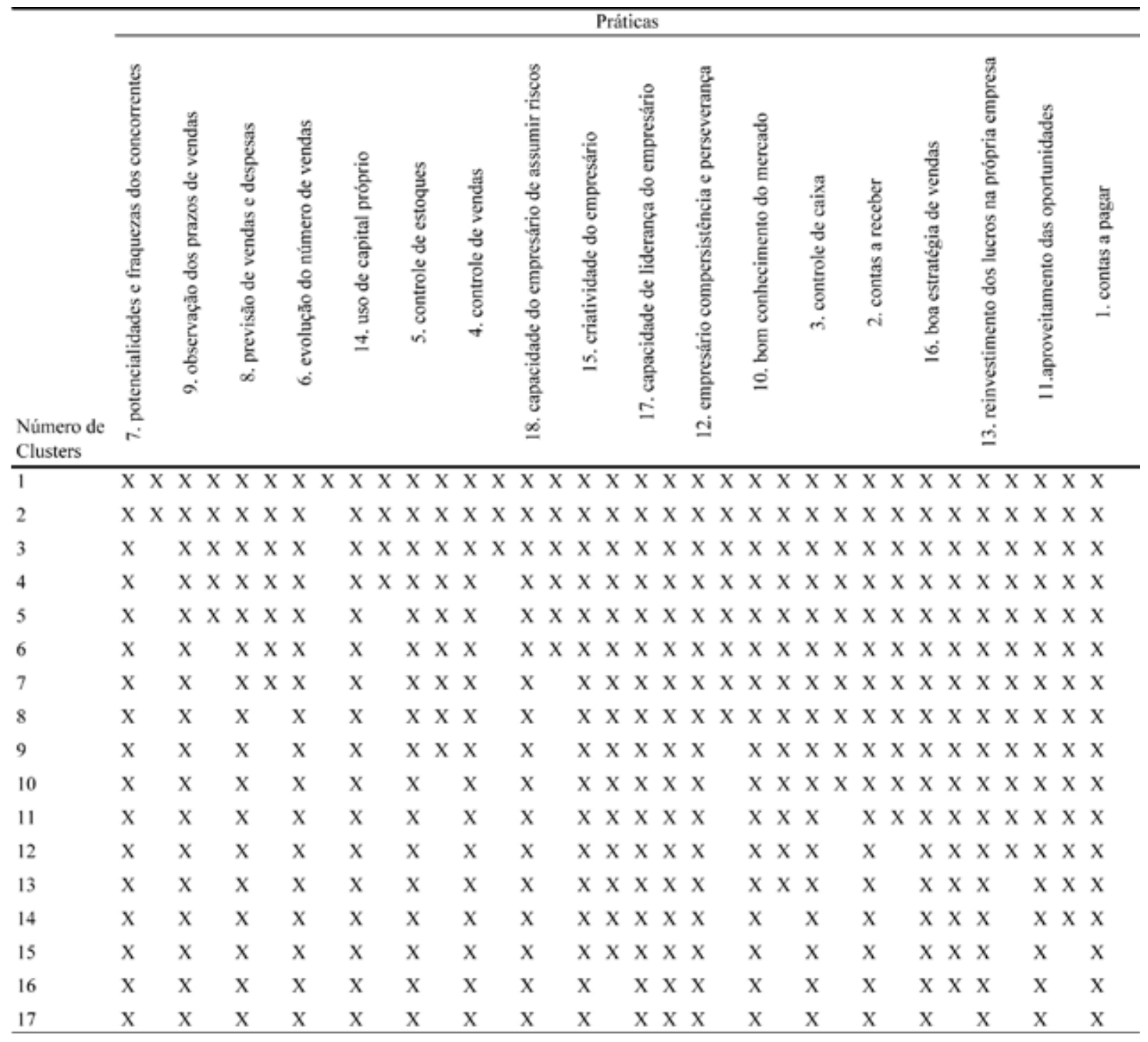

Fonte: Dados primários da pesquisa, 2009.

Além da figura 1, o método de Ward possibilita outra forma de visualização do resultado chamada de dendrograma (figura 2). O dendrograma é uma representação gráfica (gráfico em árvore) dos resultados de um procedimento hierárquico, no qual cada objeto é colocado em um eixo e o outro eixo representa os passos no procedimento hierárquico. Começando com cada objeto representado como um agrupamento separado, o dendrograma mostra graficamente como os agrupamentos são combinados em cada passo do procedimento, até que todos estejam contidos em um único agrupamento (HAIR, et al. 2005, p. 382).

Conforme demonstrado na figura 2 (o dendrograma deve ser lido da esquerda para a direita), as linhas verticais representam os conglomerados unidos e as linhas horizontais a distância euclidiana entre os mesmos. A partir deste gráfico pode-se decidir sobre o número 


\section{repc}

de conglomerados. No caso em estudo, pode-se verificar a existência de 2 conglomerados em relação as estratégias estudadas. Observe que as estratégias localizadas no aglomerado 1 apresentam menor distância, que sejam: Prática 12 (Empresário com persistência ou perseverância); Prática 17 (Capacidade de liderança do empresário); Prática 15 (Criatividade do empresário); Prática 3 (Controle de caixa); Prática 10 (Conhecimento do mercado onde atua); Prática 13 (Reinvestimentos dos lucros na própria empresa); Prática 16 (Estratégia de vendas); Prática 1(Controle de contas a pagar); e Prática 11 (Aproveitamento das oportunidades de negócios).

Do exposto, verifica-se que a grande maioria das práticas gerenciais aglomeradas no cluster 1 apresentam características relacionadas a elementos intangíveis, que são direcionadas pela própria intuição e experiência dos gestores, visto que conforme evidenciado anteriormente, o nível de instrução desses empresários é relativamente baixo. Supostamente se pode afirmar que esses atributos são reflexos da natureza do empreendimento, ou seja, são firmas individuais, enquadradas no Simples Nacional, e que ainda não dispõem de um amadurecimento empresarial suficiente para poder perceber a importância de se utilizar práticas de gerenciamento bem estruturadas e formuladas, posto que serem MPEs não as configura como sendo empresas que não precisam utilizar boas ferramentas empresariais.

Finalmente no aglomerado 2, ficaram as seguintes práticas: 2 (Controle de contas a receber); Prática 18 (Capacidade do empresário para assumir riscos); Prática 4 (Controle de vendas); Prática 5 (Controle de estoques); Prática 14 (Uso de capital próprio); Prática 6 (Evolução do volume de vendas); Prática 8 (Previsão de vendas e previsão de despesas); Prática 9 (Observação dos prazos de vendas); e Prática 7 (Conhecimento das potencialidades e fraquezas dos concorrentes). As variáveis investigadas denotam maior concentração de práticas relacionadas a elementos tangíveis, ou seja, práticas de desempenho financeiro. 
Figura 2 - Dendrograma - Método Ward (Distância euclidiana entre os clusters)

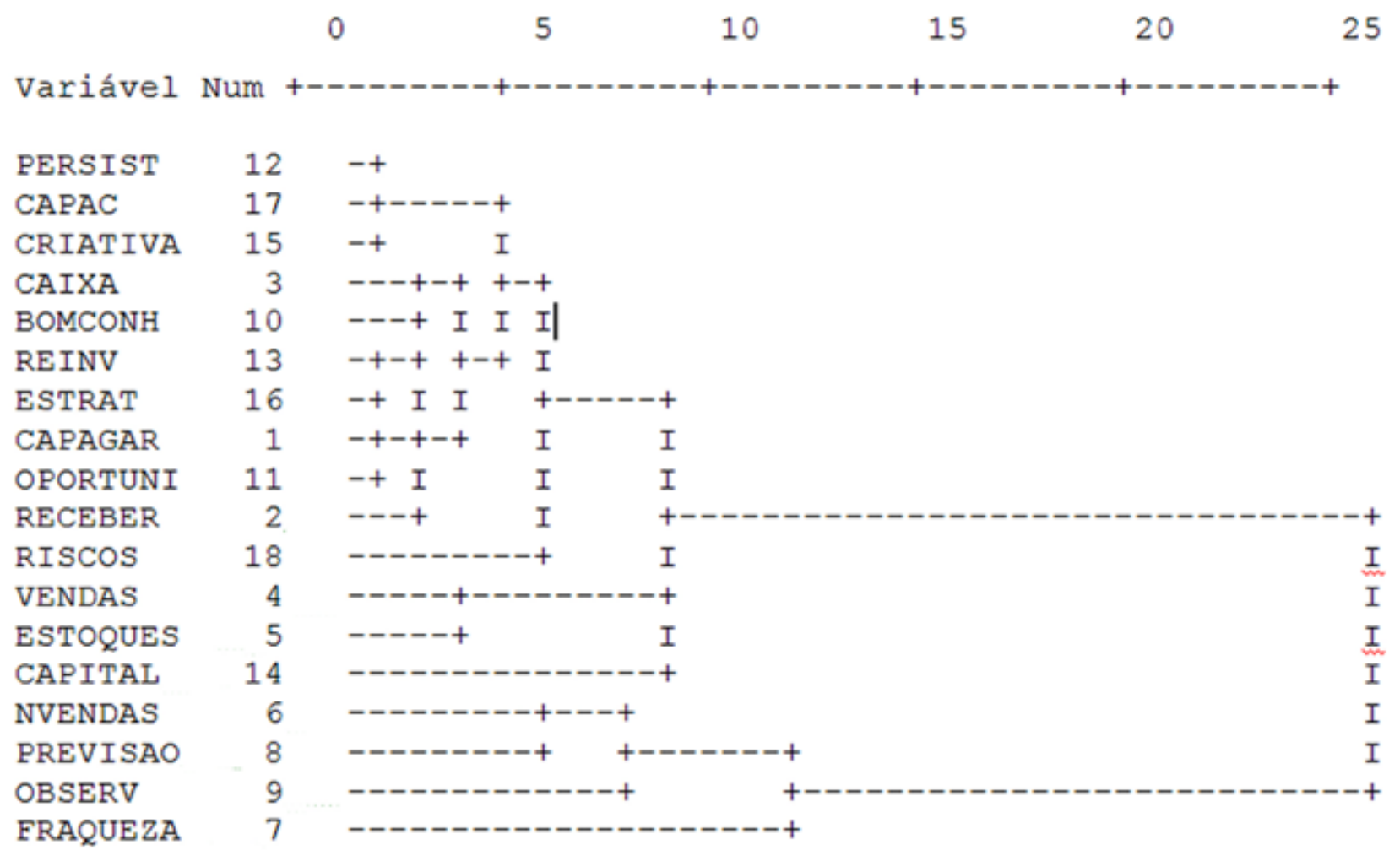

Fonte: Dados primários da pesquisa, 2009.

Visando testar a consistência interna (confiabilidade dos dados coletados), aplicouse o teste Alfa de Cronbach em cada um dos clusters encontrados. Assim, o Alfa encontrado em ambos agrupamentos aproximadamente foram iguais a 0,70 (0,67 - cluster 1) e a 0,70 (0,69 - cluster 2). Hair et al. (2005), Rodrigues e Paulo (2007) argumentam que o coeficiente Alfa de Cronbach de 0,70 é o mínimo ideal para verificar essa consistência, muito embora seja possível aceitar 0,60 para pesquisas exploratórias, o caso deste estudo.

\section{CONSIDERAÇÕES FINAIS}

Mediante ao exposto pelo presente estudo, percebe-se que as empresas varejistas do segmento de confecções da cidade de Sousa/PB constituem-se em microempresas. Ademais, as empresas em estudo são administradas em sua maioria por profissionais do sexo feminino e estas, por sua vez, são proprietárias que cursaram até o ensino médio, necessitando definir estratégias com vista a adquirir capacitação, o que supostamente poderá amenizar as dificuldades do negócio, se essa estratégia for direcionada para esse propósito. As empresas estudadas atuam no setor há mais de 10 anos e se constituem em empresas individuais enquadradas no regime de tributação Simples Nacional. 
Os resultados demonstram que existe pouca instrução entre os gestores, fato que supostamente pode estar influenciando a utilização de práticas de gestão como subsídio à decisão empresarial, posto que quanto maior for o grau de instrução maior será o conhecimento de práticas gerenciais ou medidas de desempenho que possam contribuir para a medição das atividades empresariais.

Desse modo, identificou-se que as empresas do setor em estudo fazem uso de práticas gerenciais, no entanto, isso ocorre de forma desordenada e de maneira informal, sem definir um plano estruturado e consistente, conforme preceitua a literatura específica, capaz de amenizar os gargalos existentes no processo de decisão e as mutações constantes nos cenários em que se encontram inseridas. Isso pode ocorrer pelo fato de os gestores não possuírem, pelo menos, um nível de conhecimento razoável acerca do assunto, fato que pode estar supostamente prejudicando o monitoramento de suas atividades.

Os resultados encontrados por meio das técnicas da estatística descritiva, da análise de cluster e do teste de consistência interna demonstram evidências empíricas relacionadas às práticas/estratégias empresariais que estão sendo consideradas como relevantes pelos gestores no processo de decisão.

Esses resultados corroboram o que Callado et al. (2008) dizem quando da utilização de indicadores ou práticas gerenciais como referência quantitativa de mensuração de desempenho, isso não implica, necessariamente, que haja um sistema integrado de mensuração de performance. Ou seja, de uma maneira ou de outra (no caso em estudo), os gestores investigados fazem uso de medidas de desempenho (denominado aqui de práticas gerenciais), sejam elas tangíveis (financeiras) ou intangíveis (não financeiras).

Por fim, entende-se que as práticas utilizadas pelos gestores das empresas pesquisadas são úteis e contribuem para o processo de gestão, segundo a visão dos gestores, todavia, faz-se necessário um esforço gerencial maior em busca de novas técnicas ou ferramentas na tentativa de maximizar riquezas e supostamente garantir a continuidade do empreendimento.

Embora restritos a um número limitado de empresas, entende-se que esses resultados podem oferecer algum subsídio aos gestores do segmento em estudo, bem como aos demais interessados na área. Sugere-se que o estudo seja replicado com o uso da escala de Likert e com um maior número de empresas, de modo que se possa visualizar resultados mais satisfatórios.

\section{REFERÊNCIAS}

AGUIAR, Andson Braga de; FREZATTI, Fábio. Escolha Apropriada da Estrutura de um Sistema de Controle Gerencial: Uma Proposta de Análise. In: II ANPCONT - ENCONTRO DAASSOCIAÇÃO NACIONAL DOS PROGRAMAS DE PÓS-GRADUAÇÃO EM CIÊNCIAS CONTÁBEIS. Gramado/RS. Anais... Gramado/RS, 17 a 19 de junho de 2007. 
BAVARESCO, Thaisy Piazera Fanni; GASPARETTO, Valdirene. Informações contábeis na tomada de decisão de micro e pequenas empresas: um estudo nas empresas catarinenses finalistas do Prêmio Talentos Empreendedores. In: XVI CONGRESSO BRASILEIRO DE CUSTOS - Fortaleza - Ceará, Brasil. Anais... 03 a 05 de novembro de 2009.

CALLADO, Antonio André Cunha; CALLADO, Aldo Leonardo Cunha; HOLANDA, Fernanda Marques de Almeida. Evidências Empíricas sobre o uso da Contabilidade de Custos em Micro e Pequenas Empresas: Uma Abordagem Multivariada. RIC - Revista de Informação Contábil, UFPE, v. 2, nº 2, p. 108-121, abr.-jun. 2008.

CALLADO, Antonio André Cunha; CALLADO, Aldo Leonardo Cunha; ANDRADE, Luciano Pires de. Relações entre Indicadores de Desempenho: Um Estudo Exploratório em Empresas Localizadas em Serra Talhada/PE. In: II SEMINÁRIO UFPE DE CIÊNCIAS CONTÁBEIS, 2008, Recife/PE. Anais... Recife/PE, Universidade Federal de Pernambuco, 2008.

FERREIRA, Luis Fernando Filardi; SANTOS, Silvio Aparecido dos. Mortalidade Precoce: Uma Análise das Micro e Pequenas Empresas de São Paulo. In: V ENCONTRO DE ESTUDOS SOBRE EMPREENDEDORISMO E GESTÃO DE PEQUENAS EMPRESAS, 2008, São Paulo/SP. Anais... São Paulo - Universidade Presbiteriana Mackenzie, 2008.

FERNANDES, Cláudia Alves; FREITAS, Jorge A. de Sá Brito; COSTA, Isabel de Sá Affonso da. $O$ que as microempresas aprendem: estudo de um caso no setor de informática em Juiz de Fora. In: $V$ ENCONTRO DE ESTUDOS SOBRE EMPREENDEDORISMO E GESTÃO DE PEQUENAS EMPRESAS, 2008, São Paulo/SP. Anais... São Paulo - Universidade Presbiteriana Mackenzie, 2008.

GARRISON, Ray H.; NOREEN, Eric W.; BREWER, Peter C. Contabilidade Gerencial. Rio de Janeiro: LTC, 2007.

GITMAN, Lauwrence J. Princípios da administração financeira. 3. ed. São Paulo: Harper e How do Brasil, 1984.

HAIR, Joseph F.; TATHAM, Ronald L.; ANDERSON, Rolph E.; BLACK, William. Análise multivariada de dados. 5. ed., São Paulo: Bookman Editora, 2005.

HORNGREN, Charles Thomas; DATAR, Srikant; FOSTER, George. Contabilidade de Custos: uma abordagem gerencial. v. 1, 11. ed., São Paulo: Prentice Hall, 2004. 
HORNGREN, Charles Thomas; DATAR, Srikant M.; FOSTER, George. Contabilidade Gerencial. 12. ed. São Paulo: Pearson, 2004.

KAPLAN, Robert S.; NORTON, David P. A estratégia em ação: balanced scorecard. Rio de Janeiro: Campus, 1997.

LONGENECKER, Justin G.; MOORE, Carlos W.; PETTY, J. William. Administração de pequenas cempresas: ênfase na cgerência empresarial. São Paulo: Makron Books, 1997.

MAIA, Tatiane Silva Tavares. Valores organizacionais e práticas gerenciais de empresas familiares. In: V CONVIBRA - Congresso Virtual Brasileiro de Administração, 2008.

MALHOTRA, Naresh K. Pesquisa de marketing: uma orientação aplicada. Porto Alegre: Bookman, 2001.

MAROCO, João. Análise estatística: com a utilização do SPSS. Lisboa: Silabo, 2003.

MAXIMIANO, Antonio César Amaru. Teoria Geral da Administração: da escola científica à competitividade na economia globalizada. 2. ed. São Paulo: Atlas, 2000.

PERES, L. B.; GOMES, M. B. Contabilidade orçamentária: manual da gestão governamental. Goiânia: UCG, 2000.

PIZZOLATO, N. D. Introdução à contabilidade gerencial. 2. ed. São Paulo: Pearson, 2004.

POHLMANN, Marcelo Coletto. Análise de conglomerados. In: CORRAR, L. J.; PAULO, E.; DIAS FILHO, J. M. (Orgs.). Análise multivariada para os cCursos de Administração, Ciências Contábeis e Economia - FIPECAFI. São Paulo: Atlas, 2007.

REBEHY, Perla Calil Pongeluppe Wadhy; BATALHA, M. O. Utilização de indicadores de desempenho para micro e pequenas empresas. In: ENEGEP - Encontro Nacional de Engenharia de Produção. Salvador/B. Anais..., Salvador, 2001.

RAIFUR, Léo; ALVES, Juliane Marcondes; SOUSA, Almir Ferreira de. Capital de giro na micro e pequena empresa: estrutura, financiamento e gestão. In: XVI CONGRESSO BRASILEIRO DE CUSTOS - Fortaleza - Ceará, Brasil. Anais... Fortaleza, 03 a 05 de novembro de 2009. 
ROSES, Carlos Frederico; LEIS, Rodrigo Pinto. Um estudo das condições sócio-econômicas de municípios gaúchos através da análise de cluster. Revista Administração On Line, v. 3, $\mathrm{n}^{\circ}$ 3, jul/ago/set de 2002. Disponível em: www.fecap.br/adm_online/art33/rose1.htm Acesso em: 11 de out. 2009.

ROSS, Stephen. A.; WESTERFIELD, Randolph W.; JAFFE, Jeffrey F. Administração financeira. São Paulo: Atlas, 1995.

SALES, Rodrigo Lacerda; BARROS, Aluisio Antonio; PEREIRA, Cláudia Maria Miranda de Araújo. Fatores condicionantes da mortalidade dos pequenos negócios no Município de Leopoldina - MG. In: V ENCONTRO DE ESTUDOS SOBRE EMPREENDEDORISMO E GESTÃO DE PEQUENAS EMPRESAS, 2008, São Paulo/SP. Anais... São Paulo: Universidade Presbiteriana Mackenzie, 2008.

SALTERIO, Steven; WEBB, Alan. The balanced scorecard. CA Magazine. Toronto, v. 136, $\mathrm{n}^{\circ} 6$, agosto de 2003.

SANTOS, Ademilson Rodrigues; CORDEIRO, Agnaldo Antonio Lopes; SOUZA, Diocésar Costa de; KUHL, Marcos Roberto; RIBEIRO, Roberto Rivelino Martins; MICHELS, Valdir. Um novo conceito para Contabilidade Gerencial. In: XIII CONGRESSO BRASILEIRO DE CUSTOS. 2005, Belo Horizonte/MG. Anais... Belo Horizonte, MG, 2005.

SEBRAE. Pesquisa dos fatores condicionantes e taxas de sobrevivência e mortalidade das micro e pequenas empresas no Brasil 2003-2005. Brasília, 2007.

SILVA, Daniel Salgueiro da; GODOY, José Antonio de; CUNHA, José Xavier. COELHO NETO, Pedro (Coord.). Manual de procedimentos contábeis para micro e pequenas empresas. 5. ed. Brasília : CFC : SEBRAE, 2002.

TAVARES, Mauro C. Gestão Estratégica. São Paulo: Atlas, 2000.

TAVARES, Bruno; FERREIRA, Marcos Aurélio Marques; LIMA, Afonso Augusto T. de Freitas de Carvalho. Identificação e agrupamento de fatores de relevância na investigação das práticas de gestão das micro e pequenas empresas. In: V ENCONTRO DE ESTUDOS SOBRE EMPREENDEDORISMO E GESTÃO DE PEQUENAS EMPRESAS, 2008, São Paulo/ SP. Anais... São Paulo - Universidade Presbiteriana Mackenzie, 2008. 


\section{APÊNDICE 1: Questionário de Pesquisa}

Pesquisa: Evidências Empíricas sobre Práticas Gerenciais em MPEs: Estudo no Comércio Varejista de Confecções da Cidade de Sousa-PB

I-CARACTERIZAÇÃO DO REPRESENTANTE DA EMPRESA:

01. Sexo: [ ] Masculino [ ] Feminino

02. Qual é o seu cargo/função na empresa?

03. Qual o seu tempo de experiência no setor? ano (s).

04. Qual o seu grau de instrução?

II-CARACTERIZAÇÃO DA EMPRESA:

05. Natureza Jurídica:

06. Regime de Tributação:

07. Há quanto tempo a empresa exerce as atividades? anos

08. Qual o número de funcionários da empresa? 


\section{III - ASPECTOS RELATIVOS ÀS PRÁTICAS GERENCIAIS UTILIZADAS:}

09. Marque com um X as opções abaixo em relação às práticas de gerenciamento utilizadas por sua empresa.

\begin{tabular}{|l|l|l|}
\hline \multicolumn{1}{|c|}{ Controles de Gestão } & Sim & Não \\
\hline Controle de contas a pagar & & \\
\hline Controle de contas a receber & & \\
\hline Controle de caixa & & \\
\hline Controle de vendas & & \\
\hline Controle de estoques & & \\
\hline Evolução do número de vendas & & \\
\hline Conhecimento das potencialidades e fraquezas dos concorrentes & & \\
\hline Previsão de vendas e previsão de despesas & & \\
\hline Observação dos prazos de vendas & & \\
\hline Bom conhecimento do mercado onde atua & & \\
\hline Aproveitamento das oportunidades de negócios & & \\
\hline Empresário com persistência ou perseverancia & & \\
\hline Reinvestimentos dos lucros na própria empresa & & \\
\hline Uso de capital próprio & & \\
\hline Criatividade do empresário & & \\
\hline Boa estratégia de vendas & & \\
\hline Capacidade de liderança do empresário & & \\
\hline Capacidade do empresário para assumir riscos & & \\
\hline
\end{tabular}

Desde já agradecemos pela sua valiosa contribuição na realização desse estudo. Os autores. 